International Journal of Linguistics, Literature and Translation

ISSN: 2617-0299 (Online); ISSN: 2708-0099 (Print)

DOI: $10.32996 / \mathrm{ijlt}$

Journal Homepage: www.al-kindipublisher.com/index.php/ijllt

\title{
The Social Stratification of Qaf in Egyptian Arabic
}

\author{
Aliaa Aloufi 8 (D) \\ Assistant Professor, Taibah University, Medina, Saudi Arabia \\ Corresponding Author: Aliaa Aloufi, E-mail: amsaufe@taibahu.edu.sa
}

\begin{tabular}{ll}
\hline ARTICLE INFORMATION & ABSTRACT \\
\hline
\end{tabular}

Received: July 17, 2021

Accepted: August 20, 2021

Volume: 4

Issue: 8

DOI: $10.32996 / i j l t .2021 .4 .8 .14$

\section{KEYWORDS}

Language variation, stratification, sociolinguistic, variable
The present study aims to investigate the phonological behaviour of Egyptian speakers stratified by age, gender and region in the pronunciation of the voiceless uvular plosive $/ q /$ sound. The application of sociolinguistic methodology shows that the study has observed the role of some social variables such as age, gender and region in language change. The study has concluded that the $/ q /$ sound is used by men more than women and the older generation more than the younger generation. Furthermore, the study points out the role of regional differences in the speech of Egyptian speakers as the / $q$ / sound is used by those speakers who live in rural areas more than those who come from urban areas. In sum, this study helps to enrich our understanding of language variation and change in Arabic dialect, more specifically Egyptian Arabic.

\section{Introduction}

Several Arabic sociolinguistic studies have been merged in order to explore the change in the pronunciation of certain sounds in different Arabic dialects. One major phonological variable is the voiceless uvular plosive /q/ which appeared to be extraordinarily sensitive to some of social stratification among Arabic dialects. Sociolinguists such as Abdul-Jawwad (1981), Haeri (1991) and Holes (2004) have investigated this sound in Arabic dialects in which the role of social variables such as class, age, gender as well as region was the main purpose of these studies. Thus, the aim of the current study is to investigate the role of social variables such as gender, age and region in the pronunciation change of the / $q$ / sound in Egyptian Arabic. Indeed, the study attempts to see to what extent the independent social differences of age, gender, and region among Egyptian speakers affect the pronunciation of the dependant phonological variable / $q$ / in three occurrences word-initially, medially and finally. The remainder of the study is structured as follows: the next section will provide a basic theoretical background regarding the / $q /$ sound. After which there is a section demonstrating in detail the study methodology and highlighting the adopted approach in selecting the data and informants. Then the discussion section where the results of the study is thoroughly analysed, while the conclusion, presented in the final section, provides a summary of the study and its findings.

\section{Literature Review}

In the past two decades, the change that has been occurred to the pronunciation of the /q/ in different Arabic dialects has been the centre of the debate in many sociolinguistic studies. The issue of the Qaf pronunciation has been perhaps come to the attention not only for the Arabic sociolinguists (Al-Ani, 1976; Sallam, 1980; Abdul-Jwwad, 1981), but also for those of the nonArabic sociolinguists (Garbell, 1958; Haeri, 1991; Holes, 2004). Many of the sociolinguistics studies of the /q/ find that there is considerable variety in pronunciation of the $/ q /$ in various Arabic dialects. Holes (2004: 73) provides a full description of this uvular plosive sound change in Arabic variation. This sound is either pronounced as / $/ \mathrm{l} / \mathrm{k} /$ or $/ \mathrm{g} /$ in certain places. He considers that the /q/ sound is more realised as a glottal stop in some cities such as Cairo, Damascus and Beirut. However, it becomes / $/$ / in rural places like Palestine. Holes (2004: 73) also supposes that this sound changes into /g/ in the dialects of Bedouin in central/eastern Arabia and southern Iraq. Moreover, some of the sociolinguists are more concerned with the social variation of the /q/ sound in Arabic dialects (Abdul-Jawwad, 1981; Haeri, 1991). Abdul-Jawwad's (1981) and Haeri's (1991) study both discuss the change of this sound in relation to gender. According to Abdul-Jawwad (1981: 98$)$ the / $q /$ is more related to 'toughness and

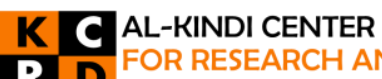

$\mathbf{R}$ D FEVELOPMENT

Your gateway to world-class research

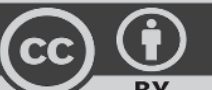

Published by Al-Kindi Center for Research and Development, London, United Kingdom. Copyright (c) the author(s). This open access article is distributed under a Creative Commons Attribution (CC-BY) 4.0 license 
masculinity', whereas the $/ \Omega$ is more associated with 'softness, femininity and sophistication'. He observes that men sometimes tend to produce the /q/ differently according to their dialect background whether it realised as /q/ or / $/$. On the other hand, he finds that women are more generally produced the $/ / /$ regardless of their dialect background. Haeri (1991) agrees with AbdulJawwad (1981) in the final remark about men and women. Conversely, some linguists observe the change of / $q /$ pronunciation in relation to age. Amongst them, Holes (2004) emphasises that in the speech of the younger generation, the /q/ is produced interchangeably as $/ \mathrm{g} /$ or $/ \mathrm{R} /$.

Some studies (Haeri, 1991; Holes, 2004) argue that despite the fact of lacking any evidence from Old Arabic concerning the pronunciation of $/ q /$, it is still historically believed that the $/ q /$ was produced as 'voiced sound' in the past. Haeri (1991) also believes that it is quite difficult for any sociolinguist to examine any change that might occur in Arabic sounds, because there is no such document which can support any sociolinguist's observation of this change in the past. However, there have been several suggestions of the early change of the Qaf sound in Arabic dialects (Garbell, 1958; Haeri, 1991). Haeri (1991) assumes that the $/ \mathrm{q} /$ is perhaps realised either as $/ \mathrm{k} / \mathrm{or} / \mathrm{g} /$ in the past. Then, she suggests that the $/ \mathrm{q} /$ becomes no longer voiced. It more realised as a voiceless sound especially in 'sedentary dialects' (1991: 95). As far as the new voiceless sound / $q /$ is concerned, she further states, it has been increasingly merged with a glottal stop. She also remarks the following (1991: 95): 'The articulation of the qaf is believed by some....include concomitant closure of glottis. If there is a glottal closure, the passage of the qaf from a voiceless uvular articulation with simultaneous glottal closure to one of only glottal closure is perhaps more phonetically plausible than it would appear at first glance (Haeri, 1991: 95)'. This might raise a fundamental question concerning the reasons behind the merger of $/ q /$ with the glottal stop. Barbot (1981) implies possible explanations regarding this merger, which might suggest a good answer for this question. Hence the root of some lexical items is a combination of three consonants, the imperative form of these lexical items are difficult to pronounce by Arabic speakers due to the combination of the /q/ and $R /$ (Barbot, 1981). Consequently, those speakers tend to drop the initial / $q$ / and produce the word either with or without a glottal stop (Barbot, 1981). As far as this dropping is concerned, Barbot (1981) attempts to generalise this example in order to explain the merger of the / $q$ / with the glottal stop. He suggests that speakers tend to drop the / $q /$ when it is initially in consonant clusters of any lexical items, no matter what is the following sound. Although, Barbot's (1981) generalisation gives us the best explanation for this merger, it just illustrates the disappearing of the /q/ when it is specifically word-initially, more precisely, not in other positions. Moreover, Garbell (1958: 211) in his study about Eastern Mediterranean dialects concerning sound change provides a possible time for this merger, between the 11th and 15th centuries. Some studies attempt to examine certain lexical items which contain the / $q$ / sound (Blanc, 1964; Al-Ani, 1976). These studies suggest that the existence of the / $q /$ in these items is perhaps as a result of borrowing from Classical Arabic. Blanc's (1964) study remarks that some speakers tend to use the /q/ in specific lexical items, which do not have any 'dialectal equivalents', certainly the /q/ is fully produced. Similarly, Al-Ani (1976: 108) conducts a study about the use of $/ q /$ in Iraq where he uses an Iraqi- English dictionary. He finds that the number of words that contains / $\mathrm{q} /$ is slightly more than of those lexical items that contains /g/ (Al-Ani, 1976: 108). Then, while examining these lexical items, he notes that the speakers of these dialects are not adopting the $/ \mathrm{g} /$ into $/ \mathrm{q} /$ but it mainly depends on the 'literary influence' on this dialect (1976: 108).

However, there are a number of quantitative studies that attempted to characterise the / $q$ / in Arabic dialects (Schmidt, 1974; Schultz, 1981; Sallam, 1980, among others). Schmidt (1974: 77) focuses on Cairene Arabic, suggests a rule what he calls 'QColloquialization' in which speakers tend to change the $/ q /$ into $/ R /$. Despite the fact that he deals with every lexical item with / $q /$ in the application of this rule, he finds that there are some lexical items in which this rule seems to be unaccountable to apply. such as /qaahira/ 'Cairo' (1974: 77). Moreover, Sallam (1980: 78) analyses the use of / $q$ / by the speakers from: Syria, Egypt, Lebanon, Jordan, and Palestine. He considers the / $q /$ in these dialects as a 'phonological variation' with the intention of 'the (Q)variable has four alternates assigned either to regional differences or (intra)-personal variation' (1980: 78). Schultz (1981) conducts a study on 'formal spoken Arabic' in Egypt where he collects the data from media, favoured with Schmidt (1974) on the 'Q-Colloquialization'. Finally, Abdul-Jwwad's study (1981) concludes with the claim that the / $q /$ and the $/ R /$ are free variation with an exception for some lexical items where the /q/ is kept as for /Qur'an/. Although some sociolinguistic studies find that the Qaf sound is increasingly replaced by glottal stop especially in the speech of Egyptian women (Abdul-Jwwad, 1981; Haeri, 1991), there might be some regions in Egypt where this sound can by fully pronounced. Such phonological difference, if found, may lead to the assumption of the existence of the / $q /$ in Egyptian Arabic. Thus, it might be possible to shed lights on this phenomenon by the application of sociolinguistic methodology to some Egyptian speakers which may help to enrich our understanding of language variation and change in Arabic dialect, more specifically Egyptian Arabic.

\section{Methodology}

\subsection{The data}

The analysed data for the current study is mainly composed of interviews with Egyptian speakers stratified by age, gender and region. Those speakers are basically asked to answer 30 questions where the expected answers are certain words that contain the / $q$ / variable in different occurrences of the word. Each of the interviews with the subjects lasts 20 minutes and the total 
conversation is nearly three hours. The interviews were actually conducted twice; in the first time, all the informants pronounce the $/ q$ / sound as much as they can as they can when they speak with me because they try to produce speech that is more likely close to Standard Arabic. Then I conduct the interview again and this time using Egyptian interviewees in order to avoid the observer's paradox. Moreover, the words used in the interviews are not randomly selected, but they were adapted from Haeri's (1991) study of the Cairene Arabic, in which she provides list of the most frequent nouns used by a speech community (Cairo) in Egypt. As far as these nouns are concerned, the position of the /q/ sound is word-initially in six words, word-medially in three words, and word-finally in one word. According to Haeri (1991: 115) the most frequent nouns used in Egyptian Arabic are as the following:

$\begin{array}{ll}\text { [mooqif] } & \text { 'position, opinin' } \\ \text { [?ilaaqa] } & \text { 'relation, relationship' } \\ \text { [qiSSa] } & \text { 'story' } \\ \text { [qa'ahira] } & \text { 'Cairo' } \\ \text { [sadiiq] } & \text { 'friend' } \\ \text { [musiiqa] } & \text { 'music' } \\ \text { [qism] } & \text { 'section, department' } \\ \text { [qur'aan] } & \text { 'Quran' } \\ \text { [qiima] } & \text { 'worth, value' } \\ \text { [qowwa] } & \text { 'power, strength' }\end{array}$

Hence the aim of the present study is to investigate the realisation of the / $q$ / sound by Egyptian speakers in certain lexical items, as the above list provided by Haeri (1991: 115) is definitely not enough to examine any change in the pronunciation of the /q/ by the Egyptian speakers. Therefore, new words which contain the /q/ sound are added in order to create three lists of words where the distinction between these words is apparently the /q/ position. Since the present study has shown in the literature review section the claim held by Blanc (1964) and Al-Ani (1976) concerning the borrowing from Classical Arabic (CA) in which certain lexical items are borrowed from CA which seems to be lacking any equivalents in Arabic dialects, though some of these words were added to the word list for this study. Indeed, the additional words are four words in which the /q/ sound is word-initially, seven words in which the $/ q /$ is word-medially, and nine words where the $/ q /$ is word-finally. The reason for this is compose three lists of words, where each list has ten words where the $/ q /$ sound is in a specific position and the purpose is pure for to the sake of clarity.

\subsection{The subject}

The number of the informants used for this study is eight divided into two groups of Egyptian speakers. Each group consists of four speakers, as the first group is the female speakers; the other group is the males. Additionally, the informants were also distributed here by age into two groups, as the first group is the younger generation who are aged between 21-33 years old while the other group stands for the older generation who are aged between 45-51 years old. Furthermore, the subjects for this study were also selected from two different areas in Egypt. The speakers who live in (Alfayom) are from a rural area in Egypt while the second group was selected from (Cairo and Alexandria) which is urban areas in Egypt. All the informants are educated and belong to the middle classes (work class) due to the study limitation. Indeed, the informants here were not randomly selected but they were carefully chosen in order to investigate the influence of gender, age and region differences on language change in Egyptian Arabic. In sum, the independent social variables in this study are age, gender and region while the phonological dependent variable is the /q/ sound in certain occurrences in the selected word list.

\section{Results and Discussion}

The data of the present study is divided into three parts according the occurrences of this sound in words. The reason for this distribution is essentially to detect any change that might occur in the pronunciation of the /q/ sound in the speech of Egyptian speakers. Furthermore, this distribution in this way can be practical in the clarification of the data as well, so as to see the effect of the occurrence of the $/ q /$ sound in a word. As such, the occurrences of this sound in words are actually analysed and discussed according to the age differences and gender among the informants. The discussion will be then divided into three main sections in which the first section is mainly about gender whereas the following section is about age differences. The third section is about the influence of regional differences such as urban and rural areas among the informants. There will be a minor section which will be devoted to the discussion of the linguistic effect of the /q/ sound in the speech of the Egyptian speakers, and, more specifically, the words used for the present study will be essentially discussed and analysed in details.

\subsection{Gender}

To begin with, the speech of the male informants in the current study shows striking results in which most of the speakers use the /q/ sound with no more than 52 of 120 of the spoken words, which can be represented by approximately $43 \%$ of the total spoken words. In word-initial position, the /q/ sound is used by the male informants in almost 22 words out of 40 spoken words 
with the percentage of $55 \%$. Then, when the occurrence of the /q/ sound is in the word medial position the informants use this sound in almost 16 out of 40 spoken words which can be represented with the percentage of approximately $40 \%$. It can be clearly seen that there is a decrease in the pronunciation of this sound when it is word-medially with $15 \%$ as it compared with the percentage of word-initially. Furthermore, when the /q/ sound is word-finally, the informants here are more likely to use this sound in roughly 13 out of 40 spoken words, which means that the percentage is much lower, nearly $32 \%$. This pattern can be represented in Figure 1 which presents the distribution of the use of /q/ sound according to gender.

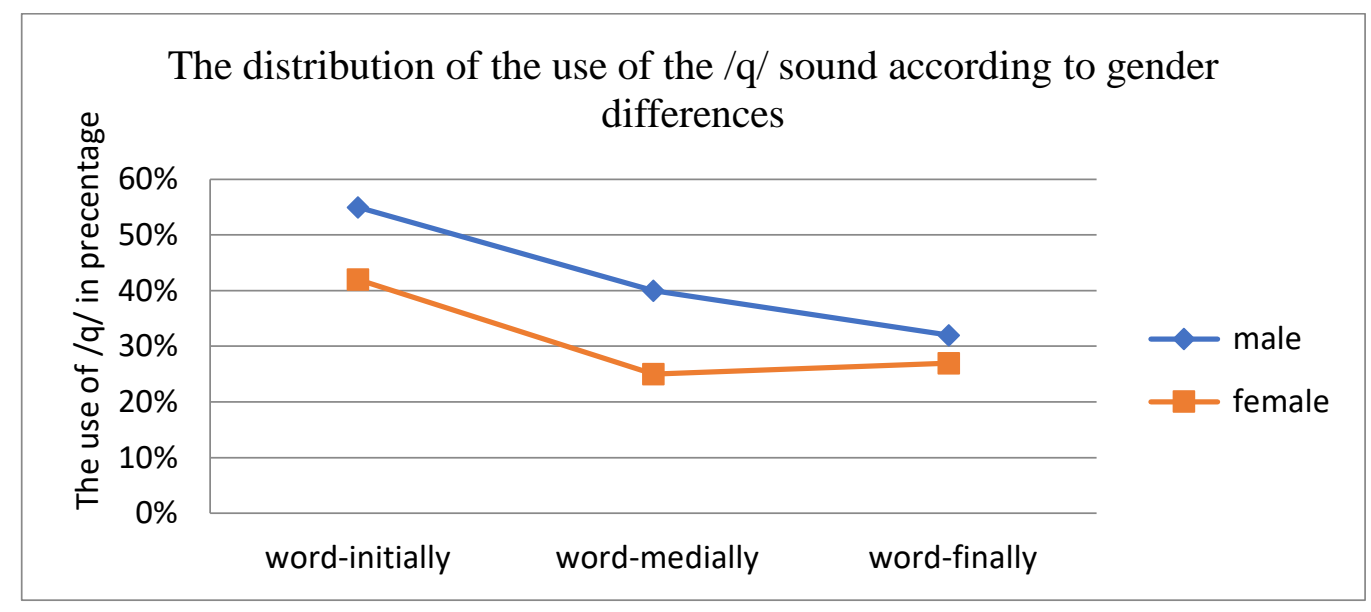

Figure1

Conversely, the speech produced by the female informants shows a slight decline in the use of the $/ q$ / sound when compared with the speech of the male informants as they use this sound in almost 38 out of 120 spoken words, which means nearly $31 \%$ of the total used words. This percentage can be distributed into three trends according to the $/ q /$ sound occurrences in the used words. Firstly, when the /q/ sound occurs in the initial position of the word, the speakers tend to pronounce it in almost 17 out of 40 spoken words with a percentage of $42 \%$, which is lower than the percentage of the male informants with $13 \%$. In word medial position, the female informants use the / $q$ / sound in roughly 10 out of 40 spoken words, which can be represented by exactly $25 \%$. It can be noted here that there is a drop off of $17 \%$ when the /q/ sound moves from the initial to the medial position. As far as the position of the $/ \mathrm{q} /$ sound is concerned, this percentage is slightly increased by $2 \%$ when this sound is in the word-final position as the speakers use the /q/ sound in nearly 11 out of 40 words, which can be represented by a percentage of $27 \%$.

The results of the present study confirm that there is a gradual change in the use of the /q/ sound in the speech of Egyptian Arabic regarding gender differences. However, this change increases more rapidly among the female speakers more than male as the female speakers tend to use the glottal stop more than male instead of the $/ q /$ sound. Although the difference between the use of the /q/ sound among Egyptian men and women is considerably different (20\%), this difference shows that men tend to use the /q/ sound in their speech more than women, which favour the results of the previous studies (Haeri, 1991, Schmidt, 1974, Abdul-Jawwad, 1981, and others) as they show evidence regarding the fact that men are more likely to use the standard form more than women.

Classical studies, which investigate the role of gender in terms of language change, such as Labov (1966), found that women use the standard variants more than men. The pattern of this study shows the opposite completely. It can be asked why Arabic dialects are different from other language dialects in the term of who leads the change among men and women. Haeri (1991) attempts to provide an explanation for this as she considers that the language with the glottal stop as (H)igh, which can confirm that that female speakers are more likely use the $\mathrm{H}$ language in their speech more than men and this explanation of the case in Arabic is a matter of which the form can be considered as the $\mathrm{H}$ form. Furthermore, Meyerhoff (2006: 218) states the following concerning the case of Arabic sociolinguistic studies, 'men using more of the overtly prestigious variants associated with Classical Arabic and women using more of the variants associated with the local colloquial variety of Arabic'.

\subsection{Age}

In addition to the gender factor, there is another difference in the informants examined in the present study, which is age. According to age differences, the informants were distributed into two major groups. The age in the first group is between 21-33 years old, which can represent the younger generation in this study. The use of the / $q$ / sound among the informants of this group can be represented by the percentage of $33 \%$ as they pronounce the sound in nearly 40 out of 120 words. The younger generation tends to pronounce the /q/ sound in almost 17 out of 40 words with the percentage of $42 \%$ when this sound is in 
word-initially. Moreover, the younger informants are more likely to use the $/ q$ / sound in roughly 12 out of 40 words when this sound is in word medial position, which can be represented by the percentage of $30 \%$. Additionally, when the occurrence of the /q/ sound is in the word final position the younger informants tends to pronounce it in almost 11 out of 40 words with the percentage of $27 \%$. Indeed, the pronunciation of the $/ q /$ sound declines with nearly $3 \%$ as a result of the position of this sound in words among the younger speakers as the lower percentage is when this sound occurs in word-finally.

The second age group, who are aged between 45-51 years, stands for the older generation in the present study. The number of words in which the older informants use the /q/ sound is actually 47 out of 120 words with a percentage of $39 \%$ which is much higher than the speech of the younger generation. This shows a noticeable decline in the use of the /q/ sound with $6 \%$. This percentage can be distributed according to the position of the $/ q /$ sound in words. In word initial position, the older informants tend to pronounce the / $q$ / sound in about 21 out of 40 spoken words with a percentage of $52 \%$. Additionally, when this sound occurs in word medial position, the informants are more likely to use it in roughly 14 out of 40 words with a percentage of $35 \%$. This percentage shows a decline of nearly $17 \%$ when the $/ q$ / sound moves from the word-initial to the medial position among all the older speakers. Furthermore, the older informants pronounce the /q/ sound in 12 out of 40 words when it is word-finally, which can be represented by the percentage of $30 \%$. It can be clearly seen that there is a gradual decline in the use of the /q/ sound among the older generation regarding the occurrences of this sound in words from the percentage of $17 \%$ to $5 \%$. Figure 2 describes this distribution according to age.

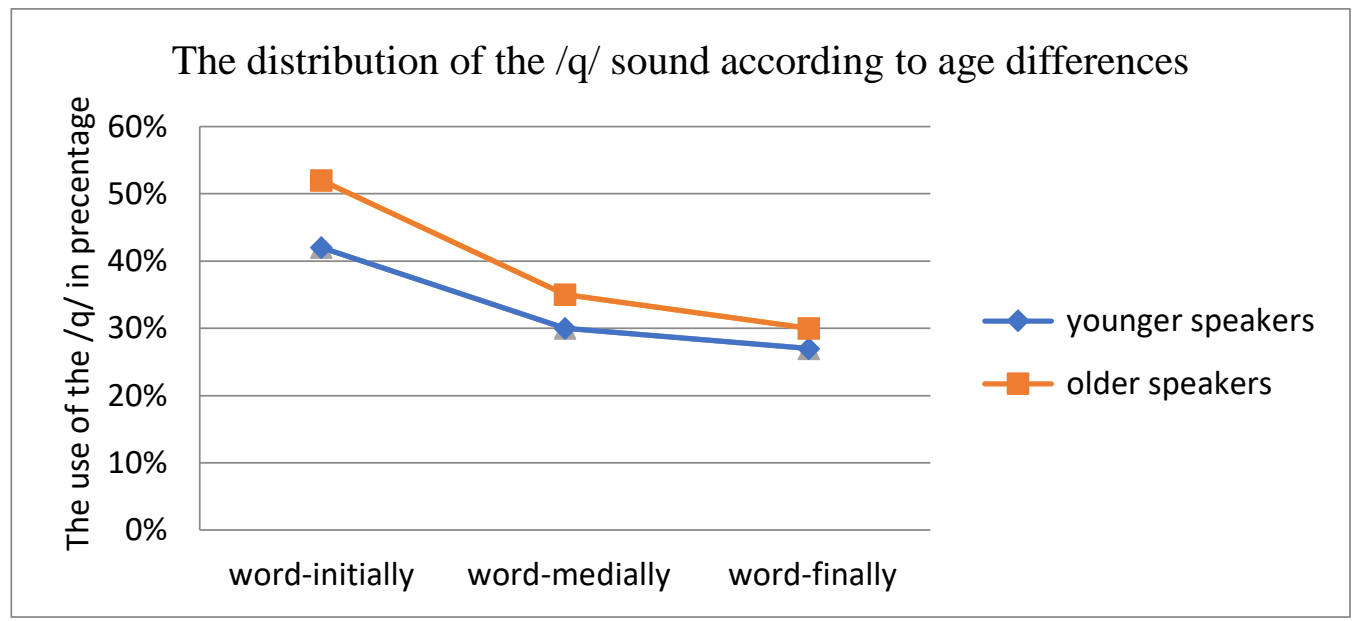

Figure 2

The results of the current study provide clear evidence concerning the role of age in language change among the speakers of Egyptian Arabic. It can be noted from previous data that the new forms of language change in Egyptian Arabic are used by the younger generation more than the older speakers. The difference between the younger and the older generations can be seen in this study as $5 \%$ although the age of the informants was estimated within 10-year intervals. This can provide evidence concerning the fact that the younger speakers are more likely to use the new form by using the glottal stop instead of the / $q$ / sound. The study's results also point out that the older generation uses the $/ q /$ sound more than the glottal stop in their speech. It can be also mentioned here that results of the present study favour the previous studies such as (Abdul-Jawwad, 1981, Holes, 2003, and others) in the term that the younger generation are more likely use the new form more than the older generation and this can be seen clearly in the behaviour of the younger subjects towards the use of the $/ \mathrm{q} /$ sound more than older subjects.

\subsection{Region}

The results show a slight difference between the speech produced by the informants from rural areas compared with those from urban areas. The difference between two groups of informants can be represented by the percentage of $8 \%$ as the informants from rural areas pronounce the /q/ sound in nearly 50 out of 120 words while the speakers from urban areas produced this sound in almost 40 out of 120 words and these results can be represented by the percentage of $41 \%$ and $33 \%$ accordingly. When the /q/ sound is in word initial position, the speakers from rural area tend to pronounce it in almost 20 out of 40 words, which can be represented by the percentage of $50 \%$. On the other hand, the /q/ sound in this position is realised in approximately 16 out of 40 words, which can be represented by the percentage of $40 \%$ in the speech of the informants from urban areas. Furthermore, when the occurrence of the $/ q /$ sound is in the word medial position it is almost realised in the speech by the speakers from urban areas in 14 out of 40 words compared with 17 out of 40 in the speech of those from rural areas and this can be represented by the percentage of $35 \%$ and $42 \%$ respectively. Finally, the subjects who live in urban areas tend to pronounce the /q/ sound in 10 out of 40 words, which can be compared with 12 out of 40 words produced by those subjects 
who live in rural areas and these results can be represented by the percentage of $25 \%$ and $30 \%$ accordingly. Indeed, it can be undoubtedly noted that the realisation of the $/ q /$ sound declines when this sound is moving from the initial position to the medial and from the medial to the final position in word the speech of subjects regardless of whether the speakers come from rural or urban areas. In short, the linguistic behaviour of the informants can be explained is that the speech of the speakers from rural areas is close to the Arabic standard more than the speech produced by those who live in urban areas. Figure 3 shows this pattern in detail.

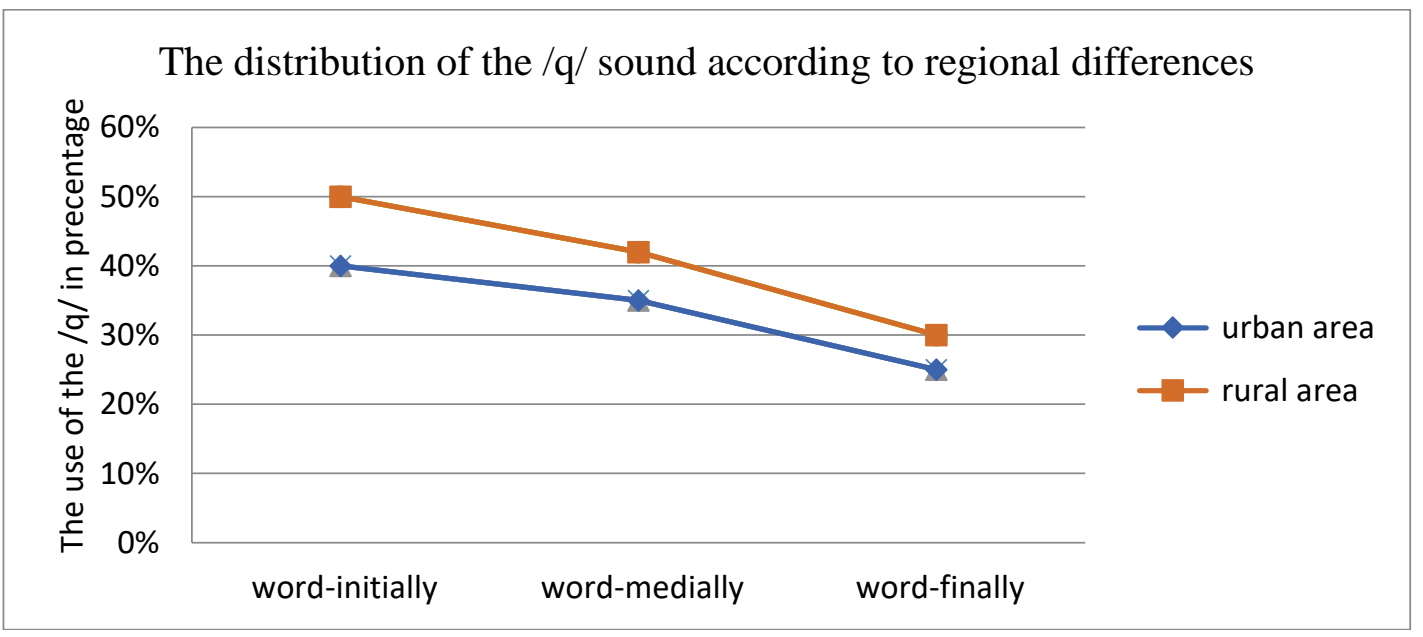

Figure 3

\subsection{Linguistic Factor}

In words selected for this study, it can be found that there is considerable observation regarding these words. None of the informants by different age, gender or region use the glottal stop with the following words: [qur'aan], [qanaat] and [qa'ahira]. The meaning of these words is 'Quran', 'Channel' and 'Cairo' respectively. It can be noted from the data that all the informants use the / $q$ / sound in these words with no exception. Therefore, it should be recommended to examine these words and try to explain the potential reasons for them. The first word is [qur'aan], which is the name of the Holy Book for Muslims and the name of this book was pronounced by all the informants with the $/ q /$ sound. The second word is [qa'ahira], which is the name of the capital of Egypt and the / $q /$ sound used by all the informants here. The last word is [qanaat], which means channel and also the /q/ sound was used by all the subjects. By examining these words, it can be clearly seen that these words are borrowed from Classical Arabic and have no equivalents in Egyptian Arabic. Hence, these words are borrowed from the standard form; the speakers of this Arabic dialect pronounce these words by using the Standard Arabic instead of using Egyptian Arabic, which was also explained by Blanc (1964). Therefore, this explanation for these words can be perhaps generalised in terms of other Arabic dialects such as Hijazi and Najdi. The generalisation here can be as the following (in any Arabic dialect, the speakers of this dialect are more likely to use the standard form in borrowed lexical items of this dialect from the standard).

\section{Conclusion}

The present study has investigated the phonological behaviour of Egyptian speakers stratified by age, gender and region in the pronunciation of the / $q$ / sound. The study has confirmed the results of some of the previous results of Haeri (1991), AbdulJawwad (1981) and Holes (2004). The application of sociolinguistic methodology shows that the study has observed the role of some social variables such as age, gender and region in language change. The study has concluded that the $/ \mathrm{q} /$ sound is used by men more than women and by the older generation more than the younger generation. Furthermore, the study points out the role of regional differences in the speech of Egyptian speakers as the / $q$ / sound is used by those speakers who live in rural areas more than those who come from urban areas. Another area can be investigated in the /q/ variable, which is the role of education as well as class in the pronunciation change in this sound in other Arabic dialects.

Funding: This research received no external funding.

Acknowledgements: This research is generously supported by Taibah University.

Conflicts of Interest: The author declares no conflict of interest. 


\section{References}

[1] Abdul-Jawad, H. (1981). 'Lexical and Phonological Variation in Spoken Arabic in Amman'. [PhD dissertation], University of Pennsylvania.

[2] Al-Ani, S. (1976). The development and distribution of the Arabic sound 'qaf' in Iraq. In Little, D. (ed.) Essay on Islamic civilization. Netherlands: Brill Archive, 48-56.

[3] Blanc, H. (1964). Communal dialects in Baghdad. Harvard University Press: Cambridge MA.

[4] Barbot, M. (1981). Evolution de l'arabe contemporain / par. Paris : A. Maisonneuve,

[5] Garbell, I. (1958). Remarks on the historical phonology of an East Mediterranean Arabic dialect. In Al-Ani, S. (ed.) Reading in Arabic Linguistics. Bloomington: Indiana University Linguistics Club, p.211.

[6] Haeri, N. (1991). 'Sociolinguistic Variation in Cairene Arabic: Palatalization and the qaf in the Speech of Men and Women'. PhD dissertation, University of Pennsylvania.

[7] Holes, C. (2004). Modern Arabic: structures, functions, and varieties. Washington: Georgetown University Press.

[8] Labov, W. (1966). The Social Stratification of English in New York City. Washington: Centre for Applied Linguistics.

[9] Meyerhoff, M. (2006). Introducing Sociolinguistics. London and New York: Routledge.

[10] Sallam, A. (1980). 'Phonological Variation in Educated Spoken Arabic'. Bulletin of the School of Oriental and African Studies, 43: 77-100.

[11] Schmidt, R. (1974). 'Sociolinguistic Variation in Spoken Egyptian Arabic'. [PhD dissertation], Brown University.

[12] Schultz, E. (1981). 'Diglossia and variation in formal spoken Arabic in Egypt'. [Ph.D. dissertation]. University of Wisconsin-Madison. 